\title{
Quasi-static and mechanical shock testing of reinforced shotcrete surface support
}

MJ Raffaldi National Institute for Occupational Safety and Health, USA

LA Martin National Institute for Occupational Safety and Health, USA

DJ Benton National Institute for Occupational Safety and Health, USA

CB Sunderman National Institute for Occupational Safety and Health, USA

MA Stepan National Institute for Occupational Safety and Health, USA

MJ Powers National Institute for Occupational Safety and Health, USA

\begin{abstract}
Mining ground control safety often depends on supporting, or at least containing, the ground between rockbolts. Different combinations of shotcrete and mesh are often used to provide surface support between bolts. Researchers with the National Institute for Occupational Safety and Health, Spokane Mining Research Division in Spokane, Washington, United States of America are measuring the mechanical performance of reinforced shotcrete used as ground support in deep underground mines where squeezing or rockbursting conditions pose significant ground control issues. Under these conditions, ground support must be able to absorb energy by yielding through large displacements while maintaining support capacity. Two test machines have been developed: (1) a high-energy high-deformation panel test for performing quasi-static tests on field-scale shotcrete panels restrained by grouted rockbolts, and (2) a fully-dynamic mechanical shock testing machine that has been retrofitted for testing $1 \mathrm{~m}$ square shotcrete panels. This paper describes these machines and results from commissioning tests. For the quasi-static machine, reinforcement of tested panels has included welded-wire mesh, chain-link fencing, synthetic fibres, spray-on polyurea liner, and combinations of these products. The dynamic machine is in an early stage of development, but results of several commissioning tests on chain-link, welded-wire, and fibre panels are discussed. Insights gained from laboratory testing may lead to ground support developments that improve safety in underground mines.
\end{abstract}

Keywords: ground support, dynamic testing, energy, shotcrete, mesh, surface support

\section{Introduction}

The Spokane Mining Research Division (SMRD) of the National Institute for Occupational Safety and Health (NIOSH), Spokane, Washington, United States of America, is conducting research into the mechanical behaviour of reinforced shotcrete used as the surface support component in mining ground support systems. The safety of underground personnel, with respect to ground control, often depends on supporting, or at least containing, ground between rockbolts. Wire mesh, fibres, and sometimes other products are used to reinforce shotcrete, forming a composite surface support system that can maintain support capacity over large ground movements. Well-designed ground support systems, in which a proper connection exists between the bolts and the mesh, can form a support system with considerable energy capacity. However, to quantify this energy capacity, high quality, large-scale testing of ground support is required. Such testing can be difficult to perform and is often not readily accessible to industry.

Researchers at SMRD initially responded to this deficiency by designing a full-scale testing device (Martin et al. 2015) and beginning a testing program (Raffaldi et al. 2016) to assess the mechanical behaviour and energy capacity of shotcrete reinforced with a variety of products used in practice including: fibres, chain-link mesh, welded-wire mesh, spray-on polyurea liners, and combinations of these products. 
Rockburst conditions in deep hard rock mines place additional demands (i.e. large strain rates and high g-forces) on ground support that cannot be evaluated via standard quasi-static testing. Therefore, SMRD researchers are utilising a large mechanical shock testing machine that subjects test panels to a controlled shock in order to investigate the influence of fully-dynamic loading on reinforced shotcrete. This paper presents an overview of these testing machines and ongoing research at the NIOSH Spokane Research Laboratory.

\section{Background}

High-energy loading environments encountered in weak and highly stressed rock, which include squeezing (Figure 1(a)) and bursting (Figure 1(b)) ground, require a support approach unique to mining engineering. Under these conditions, ground deformations are not prevented, but rather controlled to maintain safety and serviceability of the opening for its intended lifespan and maintain an adequate escape way for personnel in the event of an emergency. This requires ground support systems with well-connected components that can yield through large displacements while maintaining support capacity.

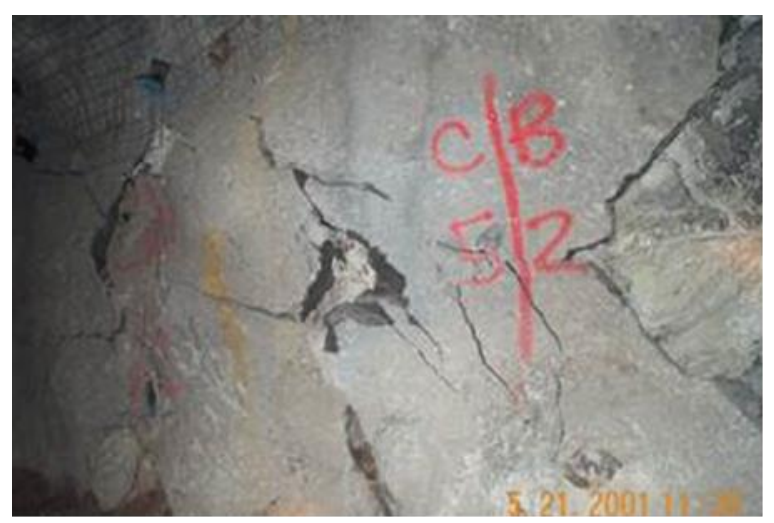

(a)

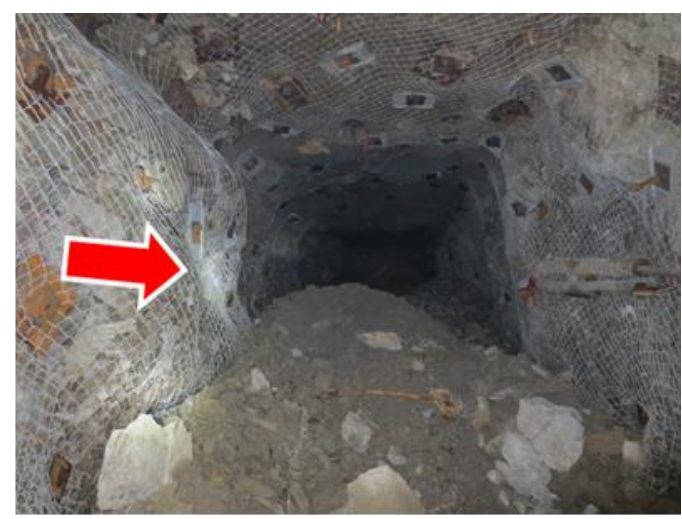

(b)

Figure 1 (a) Shotcrete damage in squeezing ground conditions; and, (b) dynamic rock ejection contained by ground support

The role of yielding ground support systems is to maintain as much rock mass strength as possible by inducing interlock of fragments, holding the rock mass together as it deforms (Ortlepp 1969). Optimally, this requires a ductile support system that can absorb energy but also has a stiff initial response so that resistance is activated quickly after installation, arresting relative displacements between rock fragments, and restricting loosening of ground.

Surface support (containment) helps maintain stability of rock between the bolts. Steel mesh, used as a stand-alone surface support, typically serves to prevent loose rock from falling or ejecting into the excavation. Standard mesh types have high rupture strength and good ductility under both static and dynamic loading (Player et al. 2008; Potvin et al. 2010). However, mesh does not provide significant resistance before displacements of $10 \mathrm{~cm}$ or more (Pakalnis \& Ames 1983; Morton et al. 2007; Player et al. 2008). On the other hand, unreinforced shotcrete is stiff and can have high initial strength, providing early resistance to rock mass deformation. It also has the additional benefit of bonding directly with the rock, promoting stability through interface shear strength and filling of rock fractures (Stacey 2001). However, unreinforced shotcrete loses virtually all of its load capacity after very small flexural displacements (a few $\mathrm{mm}$ or less).

This deficiency can be overcome by reinforcing shotcrete with steel mesh to form a composite surface support (Morgan et al. 1989; Kirsten 1993; Ortlepp \& Stacey 1998) with quasi-static energy capacities as large as $10 \mathrm{~kJ} / \mathrm{m}^{2}$ (Raffaldi et al. 2016). However, the applicability of quasi-static test results to rockburst support design is not universally accepted and quantitative test results concerning the behaviour of reinforced shotcrete subjected to dynamic loading are limited. 
The ultimate tensile strength and strain of many steels is relatively insensitive to strain rate up to a value of, at least, $10 \mathrm{~s}^{-1}$ and, in general, these values slightly increase with strain rate (Soroushian \& Choi 1987). This material behaviour is observed by comparing quasi-static and dynamic rupture loads and displacements of standard welded-wire and chain-link mesh tested in the laboratory (Player et al. 2008; Villaescusa et al. 2012).

Such observations suggest that dynamic tests are not necessary to compare the relative energy capacity of standard steel ground support products. However, this does not diminish the importance of performing such mechanical tests because there is not equivalency between quasi-static and dynamic loading; inertial forces cannot be ignored in dynamics, particularly when shotcrete, which has considerable mass, is involved. After the shotcrete fractures, it essentially becomes mass with kinetic energy that must be absorbed by the reinforcement through ductile yielding. Therefore, conceptually, the capacity of reinforced shotcrete to absorb kinetic energy of ejecting rock will decrease with ejection velocity. At very high ejection velocities, the reinforced shotcrete may essentially fail under its own inertial loads. Additionally, high g-forces and large deformations may result in pieces of shotcrete ejecting into the excavation, causing a striking hazard, even if the support system is effective in containing the rockburst. Further, products such as synthetic fibre may be sensitive to loading rate. Combining results from large-scale quasi-static tests with those from controlled, fully-dynamic shock tests may provide insight regarding the use of reinforced shotcrete for rockburst support.

\section{High-energy high-deformation test machine}

The high-energy high-deformation (HEHD) panel testing machine (Figure 2) was designed specifically for testing field-scale reinforced shotcrete panels. Although similar tests have been conducted in the past, including the works of Kirsten and Labrum (1990), Kirsten (1992, 1993), Morgan (1989, 1999), Widijanto et al. (2010), and Bernard (2010), none of these studies investigated displacement beyond $10 \mathrm{~cm}$. The new test frame can accommodate a $1.83 \mathrm{~m}$ square panel that is through bolted with rockbolts (1.2 $\mathrm{m}$ square pattern) grouted into four reinforced concrete support columns. A 1,500 kN jack with a $25 \mathrm{~cm}$ stroke is used to drive a ram with a hemispherical loading head through the shotcrete panel.

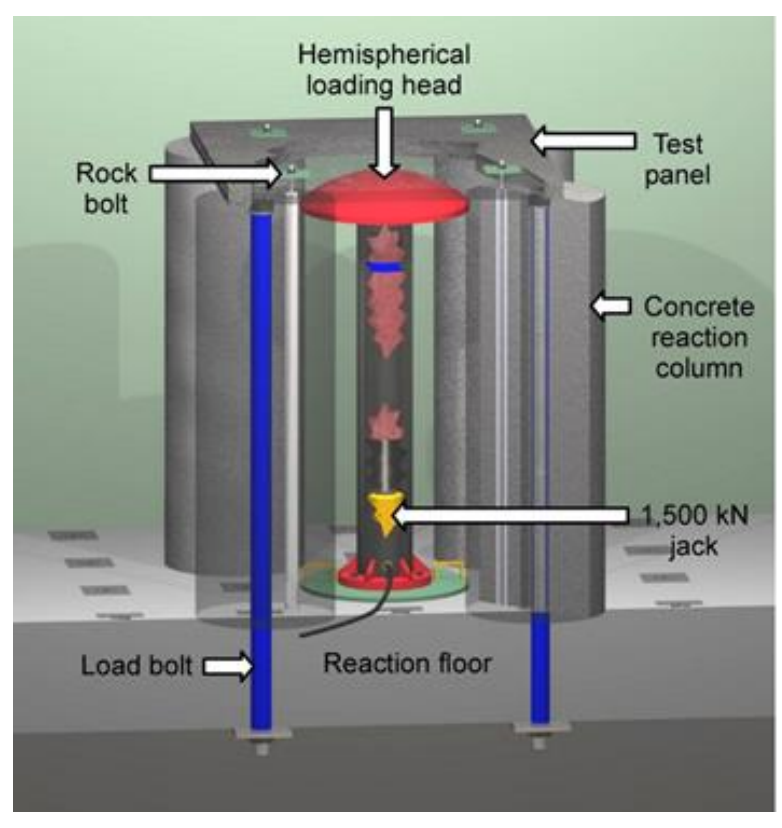

(a)

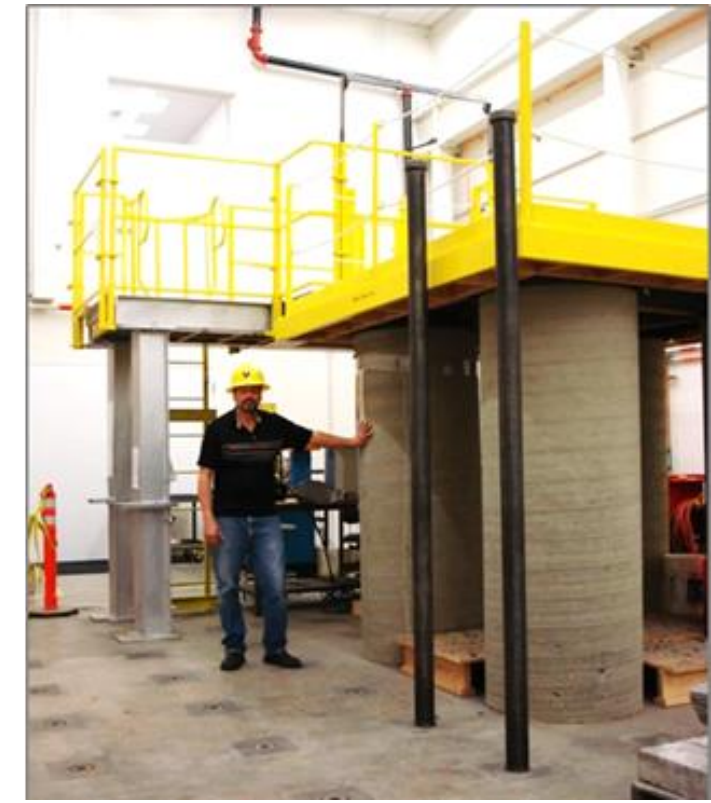

(b)

Figure 2 High-energy high-deformation test machine: (a) schematic; and, (b) photograph

The loading head geometry is designed to more realistically simulate bulging between bolts that occurs in squeezing ground. It avoids unrealistic punching failure caused by point loading, edge effects caused by square loading plates, and is more durable than a pressurised bag. The test machine design does not consider the adhesion between the rock and shotcrete, because at such large displacements adhesion is lost. 
Flexural strength of the concrete is also exceeded at large deflections, and the surface support typically forms a bag, containing the rock between the bolts. Thus, the post-fracture performance is of primary interest. The test machine also ignores the effect of lateral constraint provided by a contiguous layer of shotcrete, which tends to increase the initial flexural strength via development of hoop stresses (Bernard 2010). Shotcrete in underground mining is rarely applied in such a way, and even so, such affects would be minimised after initial flexural cracking.

A laboratory photogrammetry system (Benton et al. 2015b) is used to measure the geometric changes of the panels, including volume changes and panel cracking. These measurements can be correlated with the load and displacement data allowing visual observation to be related to the applied force and displacement. The photogrammetric analysis techniques used to perform these calculations are described in detail by Benton et al. (2015a, 2015b). Further detail on the HEHD panel testing machine and photogrammetric methods is available in previous publications (Martin et al. 2015; Raffaldi et al. 2016).

\section{$4 \quad$ High-energy high-deformation quasi-static commissioning test results}

A series of HEHD panel tests was performed on reinforced shotcrete test panels after 28 days of curing. Reinforcement products included: BarChip $54{ }^{\circledR}$ synthetic macro fibres (length: $54 \mathrm{~mm}$, dosage: $6.5 \mathrm{~kg} / \mathrm{m}^{3}$ ); TurboLiner ${ }^{\circledast} 5502$ polyurea liner; bare carbon steel, $10.2 \mathrm{~cm}$ mesh size, No. 4 gauge, welded-wire mesh; and $5.1 \mathrm{~cm}$ mesh size, No. 9 gauge, galvanised chain-link mesh. The combination of both fibres and chain-link mesh was also tested. Construction methodology and 28 day concrete compressive and tensile strengths are provided by Martin et al. (2015) and Raffaldi et al. (2016).

\subsection{Load capacity}

Figure 3(a) provides a comparison of the force-displacement response for all tested panel types; each force-displacement curve is an average result of two or three individual tests. Figure 3(b) provides the energy-displacement response and is discussed in Section 4.2. The apparent residual strength of the unreinforced panel is a result of the self-weight of the shotcrete and the clamping force of the bolt plates. The actual load-bearing capacity is lost after less than $2 \mathrm{~cm}$ of displacement as shown by the dashed line in Figure 3(a).

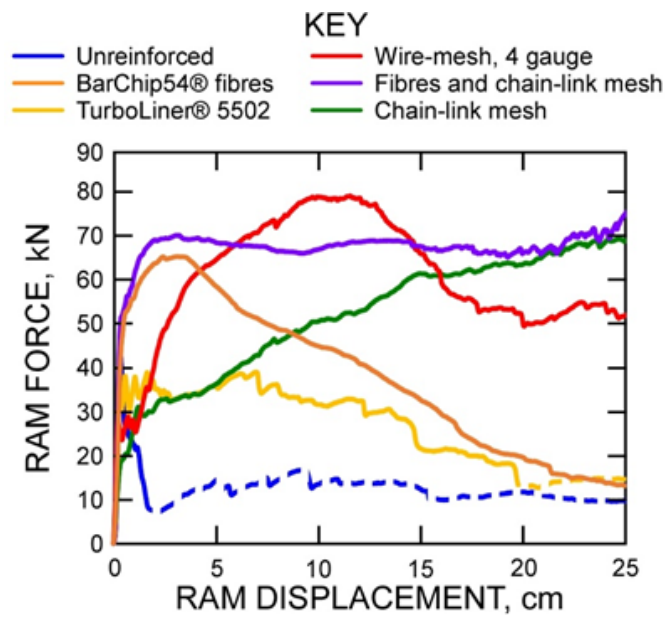

(a)

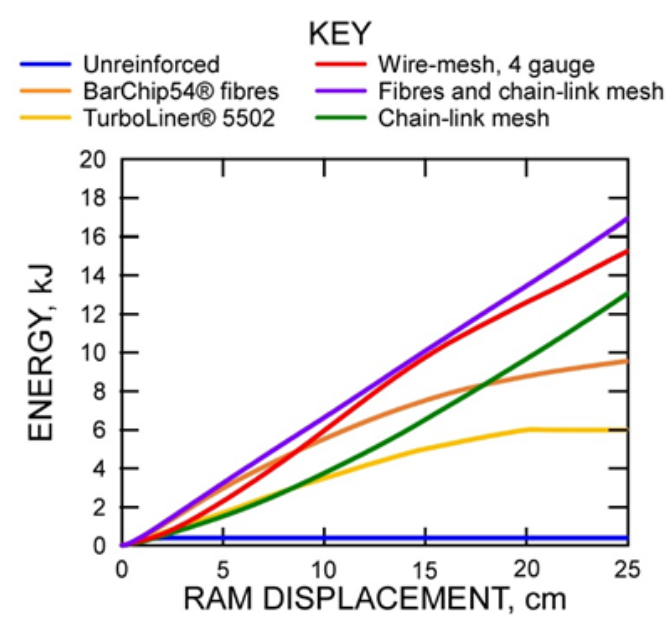

(b)

Figure 3 (a) Ram force; and, (b) energy versus displacement for average HEHD test results

All reinforcement types significantly outperformed the polyurea-lined panels, which provided no increase in peak strength. Observation suggested that this particular type of liner progressively tore open during the test with virtually no plastic deformation of the liner occurring between panel cracks. Other spray-on liner products may provide better results. 
Introduction of synthetic fibres into the shotcrete mix greatly enhanced initial rupture strength and post-peak performance, but the fibres gradually pulled out over large displacements, progressively reducing support capacity. The steel-mesh reinforced panels were able to yield and maintain significant support capacity even after $25 \mathrm{~cm}$ of ram displacement. However, while the resistance of the chain-link reinforced panels were continuing to increase at the conclusion of the test, the welded-wire mesh panels had already reached peak resistance and were unloading as the mesh failed at the welds. The combination of both fibre and chain-link forms a surface support with a nearly ideal force-displacement behaviour.

It is important to note that for mesh-reinforced panels, the mesh was located in the bottom one-third of the panel thickness, above the neutral axis (on the loading ram side). This is not ideal placement to optimise flexural resistance but is more representative of shotcrete sprayed over mesh in a mine. Furthermore, this limits concentrated tensile displacements of the steel strands between wide cracks that occur at large panel deflections allowing the properties of the mesh to be more effectively utilised. This behaviour contrasts with the results of large-scale panel tests reported by Kirsten and Labrum (1990) and Kirsten (1993), which tended to exhibit displacement-softening behaviour as wire strands snapped after deflection exceeded $2.5 \mathrm{~cm}$. Though not explicitly mentioned, it appears that in those tests, mesh was located below the neutral axis. The sensitivity of panel performance to the location of mesh placement with respect to the neutral-axis should be investigated in future testing.

\subsection{Energy capacity}

The energy capacity of shotcrete, also known as 'toughness', is quantified as the area beneath the force-displacement curve. By integrating the average force-displacement response with respect to displacement, energy-displacement plots were developed, provided in Figure 3(b). These results show that while the polyurea-lined and fibre-reinforced panels have effectively lost support capacity and are no longer able to absorb energy at the conclusion of the test, all steel-mesh reinforced panels are continuing to absorb energy after $25 \mathrm{~cm}$ of deflection. The energy capacity of the fibre-reinforced panels is comparable to that of the steel-mesh (welded-wire, chain-link) reinforced panels to a displacements near $10 \mathrm{~cm}$. However, the fibre panels are displacement-softening while the steel-mesh panels, particularly those with chain-link, exhibit much more stable force-displacement responses.

\subsection{Photogrammetric and visual observation}

Fibre-reinforced panels had the additional benefit that the fibres tended to hold the broken shotcrete together, reducing the likelihood of falling blocks. While the plain shotcrete mix tended to form a spider-web fracture pattern, resulting in loose blocks of concrete that might dislodge and fall, fibre-mix shotcrete tended to crack into larger, apparently more stable sections (Figures 4(a) and 4(b)).

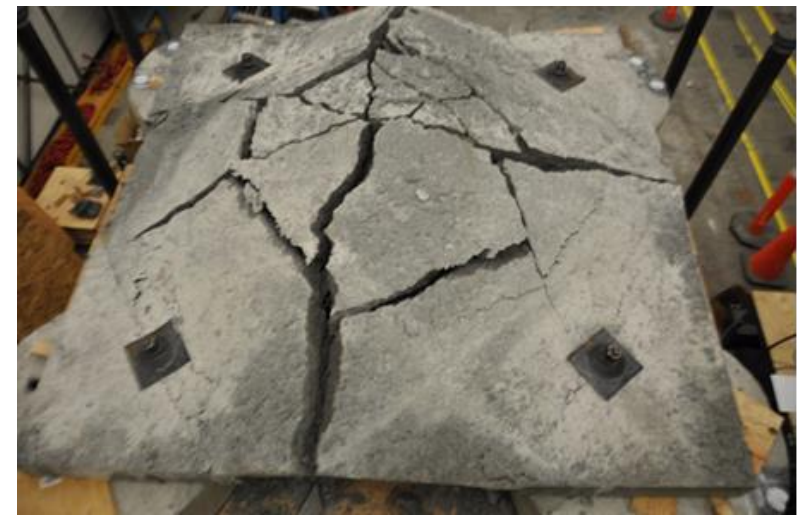

(a)

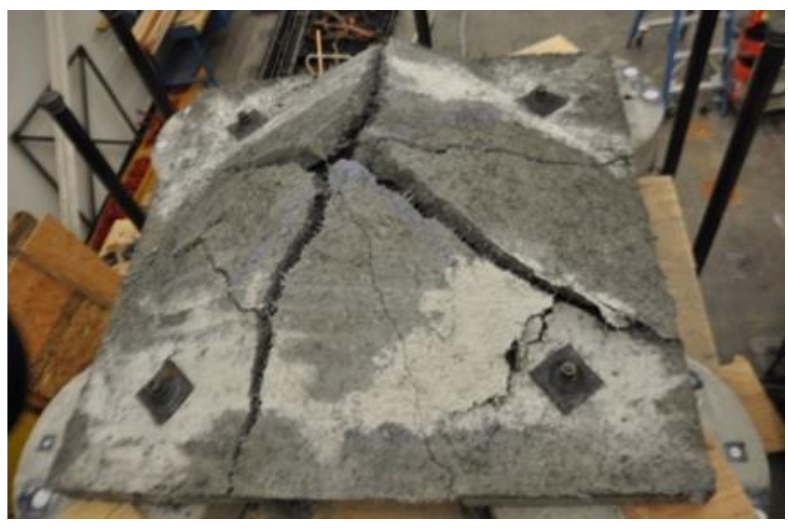

(b)

Figure 4 Post-test condition of: (a) chain-link reinforced shotcrete; and, (b) fibre and chain-link reinforced shotcrete panel 
After each test, crack widths at several locations on the upper surface of the panels were measured at $5 \mathrm{~cm}$ ram displacement intervals using photogrammetry. This allows for visual observation of damage to be correlated with remaining load and energy capacity. Figure 5 shows the force-displacement response for three individual tests on an unreinforced, fibre-reinforced, and fibre and chain-link reinforced panel. Markers show the location along the curves at which various size cracks formed. Figure 5 considers only the flexural loading mechanism induced by the HEHD test but shows that if shotcrete is reinforced with steel mesh, the composite surface support can provide significant load capacity even when the exposed surface of the shotcrete is highly deformed with very large fractures present. Where long-term support is required, opening of cracks exposes the reinforcement to air and humidity that may lead to corrosion, reducing load capacity. Such additional factors must also be considered in support design and rehabilitation plans.

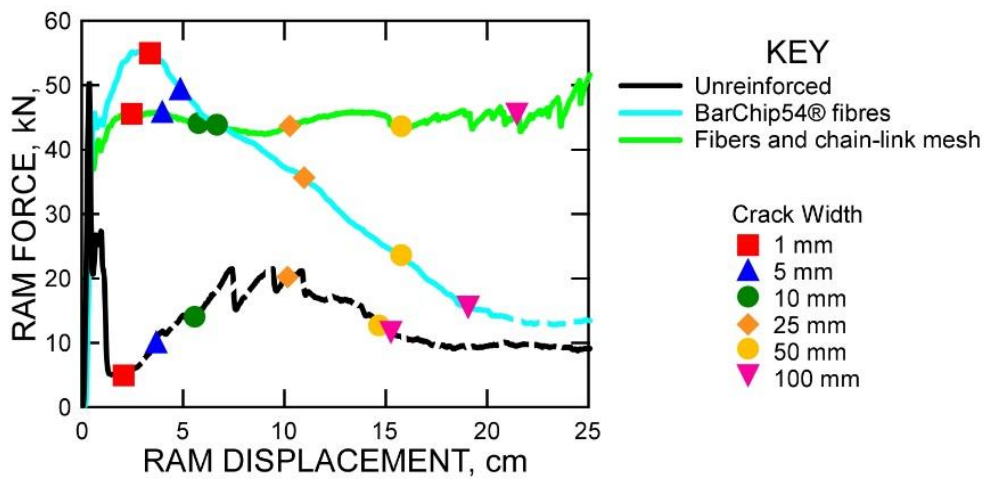

Figure 5 Force, displacement and crack width relationships for several example panel tests

\section{$5 \quad$ Dynamic shock test machine}

An MTS IMPAC 3636 Mark II mechanical shock test machine is used to perform dynamic shock testing of reinforced shotcrete panels. The testing machine is shown in Figure 6 . The boundary conditions are such that loading results in a determinate break according to yield line theory (Johansen 1972). As a result, testing is reproducible, results can potentially be related back to reinforced concrete theory, and can be compared to static determinate tests such as the round determinate panel (RDP) test.

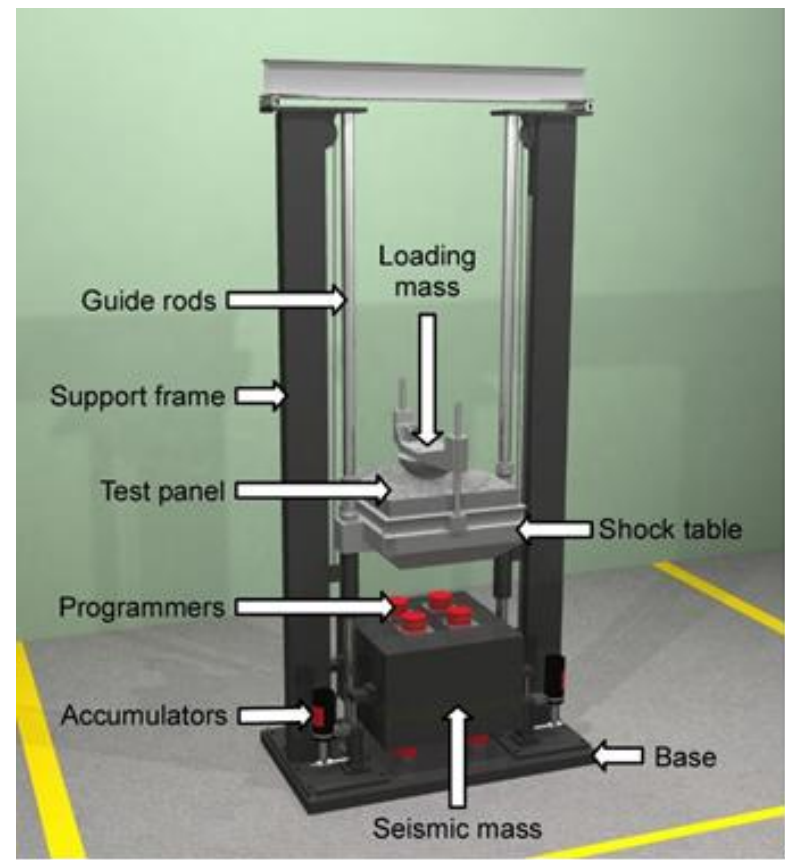

(a)

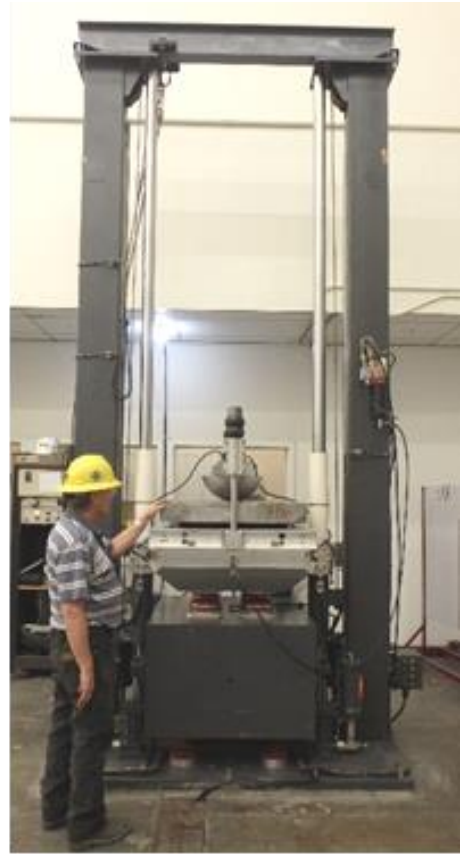

(b)

Figure 6 Dynamic shock test machine: (a) schematic; and, (b) photograph 
The testing machine incorporates similar momentum-transfer concepts as developed and implemented at the Western Australian School of Mines (Player et al. 2004). However, rather than quantifying maximum energy capacity, the test machine is designed specifically to investigate the behaviour of reinforced shotcrete subjected to a range of extreme rates of strain and high g-forces.

\subsection{Description of test machine}

The IMPAC 3636 Mark II consists of a frame assembly composed of $7.62 \mathrm{~cm}$ diameter steel guide rods attached to a thick steel base plate. The base plate distributes the impact load over a wide area to a specially designed reinforced concrete floor. Hydraulic lift cylinders and a cable system are attached to the base. A $1 \mathrm{~m}$ square shock table with a pneumatic braking system is held in alignment by the guide rods. Additionally, a massive steel billet, supported by a nitrogen-accumulator suspension assembly, dampens much of the impact load. The machine can accommodate a maximum drop height of $2.5 \mathrm{~m}$ with a corresponding impact velocity near $7 \mathrm{~m} / \mathrm{s}$ in freefall. Larger velocities could be achieved using elastic shock cords if required.

The testing machine consists of four major components, the: (1) loading-mass, (2) test panel, (3) shock table, and (4) seismic mass. The loading-mass is a $50 \mathrm{~kg}$ high strength aluminium alloy weight supported by the test panel. The purpose of the loading-mass is to induce external loading on the test panel during impact, analogous to loose rock ejecting between reinforcement. The loading-mass is held in alignment by two $3.8 \mathrm{~cm}$ diameter guide rails that are attached to the shock table, also made of high-strength aluminium. The test panel is supported at its four corners by four hemispherical seated pin supports, forcing a determinate break that conforms to yield line theory.

The seismic mass, a 4,000 kg steel billet supported by a nitrogen accumulator system, serves as a buffer to dampen the impact felt by the concrete test floor. Special elastomer pads, called programmers, are fixed to the bottom of the shock table and top of the seismic mass. By using pads of different stiffness and thickness, the duration of impact can be controlled, varying the peak deceleration of the shock table, thus changing the dynamic forces acting on the test panel.

The total test capacity of the shock table is $360 \mathrm{~kg}$. A $100 \mathrm{~mm}$ thick test panel typically weighs about $160 \mathrm{~kg}$, therefore, the largest loading-mass that could be used at maximum drop height is roughly $200 \mathrm{~kg}$. Therefore, for a freefall drop, the maximum kinetic energy of the loading-mass that can be generated at an impact velocity of $7 \mathrm{~m} / \mathrm{s}$ is $5 \mathrm{~kJ}$. For a $0.80 \mathrm{~m}$ wide panel this is roughly $7.5 \mathrm{~kJ} / \mathrm{m}^{2}$. Actual energy input will depend on the properties of the test panel and the programmers.

The testing system is fully instrumented with an array of accelerometers, position encoders, and pressure transducers. These instruments are read by a high-speed data acquisition system (reads up to $500 \mathrm{kHz}$ ) and usually down-sampled to $20 \mathrm{kHz}$. With the collected data, a history of position, velocity, and acceleration of any major machine component, as well as the pressure-displacement response of the accumulator pistons, can be constructed for the entire duration of the test.

\subsection{Description of dynamic shock test}

Several key parameters define the shock loading. These are the: (1) pulse-shape, (2) peak-deceleration, and (3) pulse-duration. These three parameters are primarily influenced by the programmers. The 'pulse-shape' is the shape of the shock table deceleration versus time plot during impact. To produce a half sine pulse, the programmer should have the characteristics of a linear spring with no damping. If the spring characteristics of the programmer are non-linear, the pulse shape becomes haversine. 'Peak-deceleration' is the maximum amplitude of the shock table deceleration during impact. The 'pulse-duration' is the time duration of the impact defined from $10 \%$ of the shock table peak deceleration on the rise side to $10 \%$ on the fall side.

During the test, the drop assembly, consisting of the shock table, test panel, and loading-mass, is raised to the drop height required to generate the user-specified impact velocity. At this point, the drop assembly is in static equilibrium. The assembly is then released and begins to accelerate uniformly toward the seismic mass under the influence of gravity. The maximum velocity is attained just before impact. Figure 7 shows 
time histories of position, velocity, and deceleration of the shock table during impact for a pre-commissioning test $(3.2 \mathrm{~m} / \mathrm{s}$ impact velocity) performed on a cast concrete panel reinforced with a low-strength mesh used in residential driveways. In Figure 7, the location from which the shock table was dropped is taken as the zero datum. The drop height was 0.55 metres. Figure 8 shows the relative position and velocity of the loading-mass with respect to the shock table, as well as the deceleration of the loading-mass. The relative position and velocity is zero until the shock table impacts the seismic mass.

At impact, the shock table begins to decelerate, decelerating the test sample (which is supported by the shock table via four pin supports). The shock table and seismic mass are in constant contact during the impact. Because of the relative mass between the drop assembly and the seismic mass, the nitrogen pressure (above system balance of 3.4 MPa) in the accumulators (which support the seismic mass) has little effect on the shock table motion. The effect of changing accumulator pressure and programmer stiffness on the resulting shock loading are shown in Figures $9(a)$ and $9(b)$, respectively.

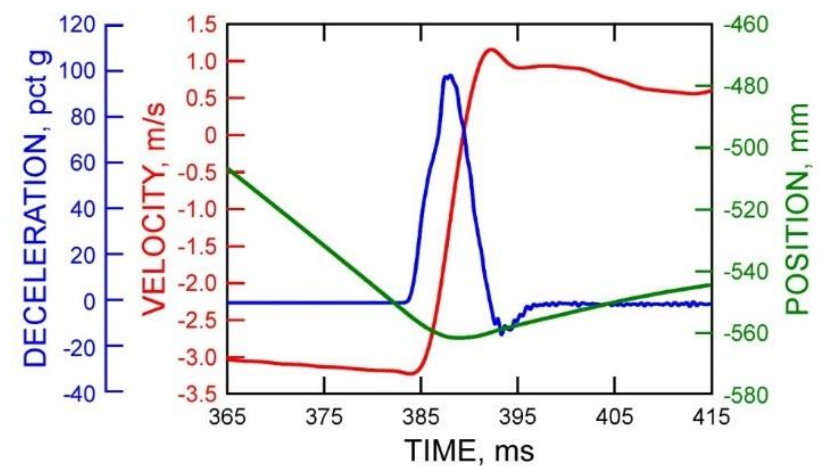

Figure 7 Position, velocity, and deceleration of the shock table versus time during the impact

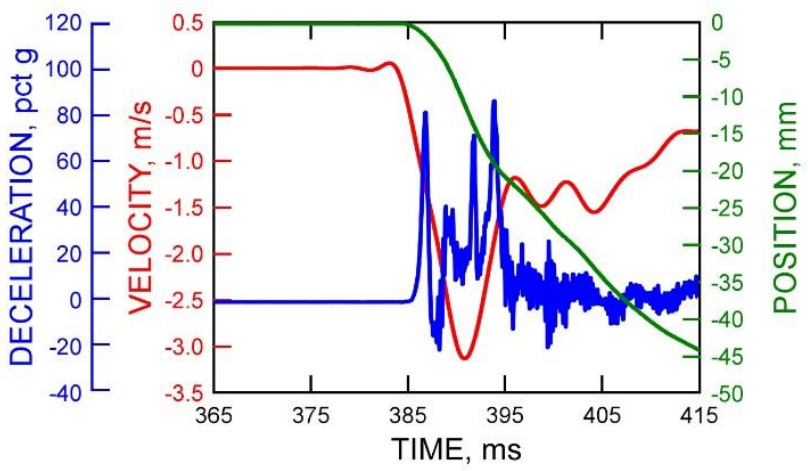

Figure 8 Position and velocity of loading-mass relative to shock table, and deceleration of loading-mass

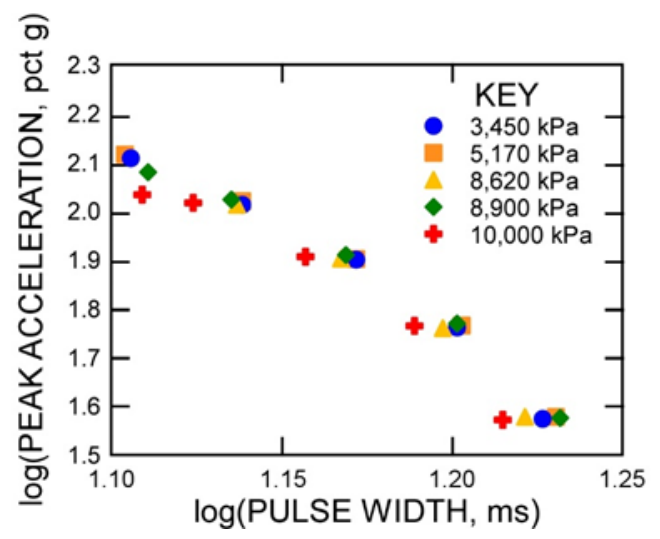

(a)

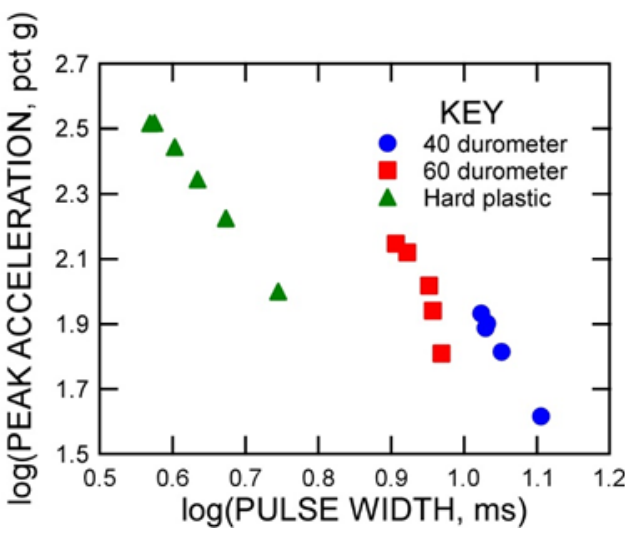

(b)

Figure 9 Effect of changing: (a) nitrogen pressure; and, (b) programmer stiffness on shock loading 
After impact, the shock table is moving more slowly and in the opposite direction, while the seismic mass is now in motion. The velocities of the shock table and seismic mass after impact depend on the coefficient of restitution for the impact. As the shock table is decelerated, the relative velocity between the loading-mass and the shock table increases from zero, resulting in a net displacement. The test panel deforms as a result of its own momentum, and momentum driving the loading-mass into the panel. As the loading-mass is resisted by the test panel, the force between the loading-mass and test panel increases, measured as a deceleration of the loading-mass. The panel deforms elastically until fracture, at which time tensile stresses are redistributed to the reinforcement, which will rupture or yield depending on the mechanical properties. For this particular test, the resulting loading from the $3.2 \mathrm{~m} / \mathrm{s}$ impact completely failed the concrete panel, rupturing the steel reinforcement wires. The determinate break pattern is shown in Figure 10(a), while the necking down of the failed reinforcement is shown in Figure 10(b), indicating tensile failure.

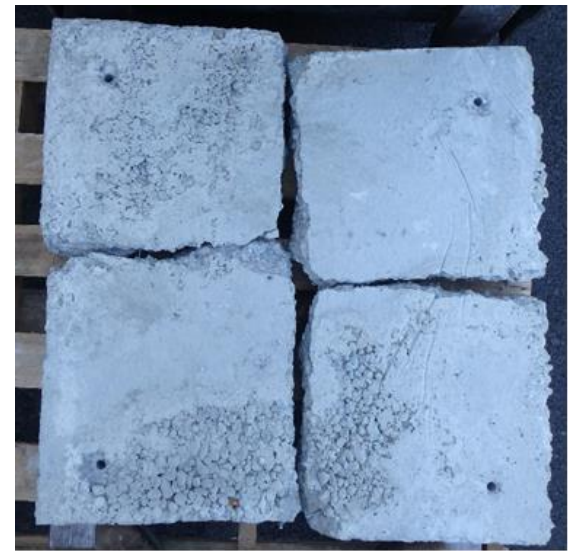

(a)

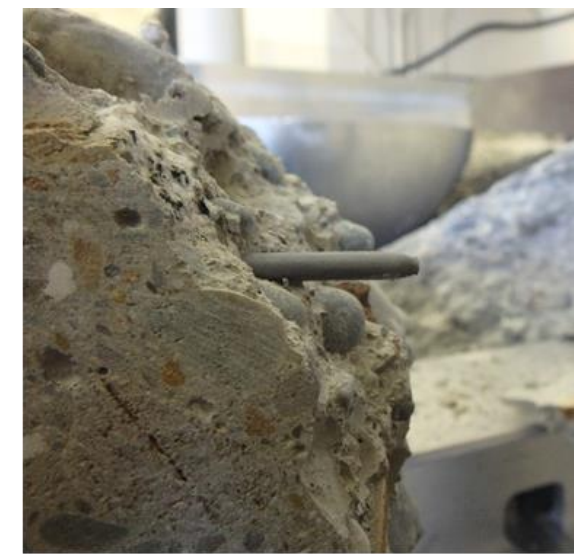

(b)

Figure 10 Post-test photos of $3.2 \mathrm{~m} / \mathrm{s}$ impact test on concrete reinforced with field fence showing: (a) the induced determinate break; and, (b) necking down of failed reinforcement steel

In Figure 7, the first deceleration peak of the loading-mass (near 100.g) is the initial resistance and failure of the concrete. The subsequent peaks are associated with the loading and failure of the reinforcement wires. At roughly 395 milliseconds ( $\mathrm{ms}$ ), the loading-mass deceleration returns to zero, indicating that it is no longer being resisted by the test panel. At the same time, the relative velocity of the loading-mass with respect to the shock table stops decreasing at about $1.4 \mathrm{~m} / \mathrm{s}$, indicating that the test panel has completely failed (if the panel had remained intact, the relative velocity of the loading-mass with respect to the shock table would have decreased to zero). It is important to remember that the loading-mass weighs only $50 \mathrm{~kg}$, while the test panel weighs roughly $150 \mathrm{~kg}$. Therefore, the dynamic loading induced as a result of the panels own inertia is considerable but complex, and not directly measurable. Lastly, the motion of the loading-mass is only an indirect measurement of how the panel load capacity changes during the test.

\section{Dynamic shock commissioning test results}

A series of shock tests were performed on $10.1 \mathrm{~cm}$ thick shotcrete panels reinforced with a variety of products, including welded-wire mesh, chain-link mesh, and synthetic macro fibres (the same products discussed in Section 4). A total of two drop tests were performed for each reinforcement type. For the welded-wire and chain-link reinforced panels, one test was performed with the reinforcement located above the neutral axis, and the other with the reinforcement below the neutral axis. For the fibre-mix panels, the fibre density was $6.5 \mathrm{~kg} / \mathrm{m}^{3}$. Table 1 provides a summary of the test panels and test configurations for each panel tested. The 28 day uniaxial compression and splitting tensile strength for the mix is provided, but the panels had all aged more than one-year at the time of testing. 
Table 1 Properties of concrete panels tested in the dynamic shock machine

\begin{tabular}{llllll}
\hline $\begin{array}{l}\text { Panel ID } \\
\text { (number) }\end{array}$ & $\begin{array}{l}\text { Weight } \\
(\mathbf{k g})\end{array}$ & $\begin{array}{l}\text { Reinforcement } \\
\text { (description) }\end{array}$ & Notes & $\begin{array}{l}\text { 28 day UCS } \\
\text { (MPa) }\end{array}$ & $\begin{array}{l}\text { 28 day STS } \\
\text { (MPa) }\end{array}$ \\
\hline CM-03-4W & 159 & Welded-wire & Above neutral axis & $37.9^{*}$ & $\mathrm{n} / \mathrm{a}$ \\
\hline $\mathrm{CM}-04-4 \mathrm{~W}$ & 156 & Welded-wire & Below neutral axis & $37.9^{*}$ & $\mathrm{n} / \mathrm{a}$ \\
$\mathrm{CM}-05-\mathrm{CL}$ & 153 & Chain-link & Below neutral axis & 50.2 & 6.3 \\
$\mathrm{CM}-07-\mathrm{FB}$ & 166 & Synthetic fibre & $6.5 \mathrm{~kg} / \mathrm{m}^{3}$ & 48.8 & 6.3 \\
$\mathrm{CM}-08-\mathrm{FB}$ & 154 & Synthetic fibre & $6.5 \mathrm{~kg} / \mathrm{m}^{3}$ & 48.8 & 6.3 \\
\hline $\mathrm{CM}-09-\mathrm{CL}$ & 152 & Chain-link & Above neutral axis & 50.2 & 6.3 \\
\hline
\end{tabular}

* Unconfined Compressive Strength and Splitting Tensile Strength tests performed after 20 days of curing

The target impact velocity for the tests was $3.2 \mathrm{~m} / \mathrm{s}$. For a $50 \mathrm{~kg}$ loading-mass, this corresponds to a kinetic energy at impact of $0.25 \mathrm{~kJ}$. The programmed shock pulse-duration was $8 \mathrm{~ms}$, and resulted in an average peak-deceleration of around $95 . \mathrm{g}$. The peak deceleration of the loading-mass and relative velocity between the loading-mass and shock table are two measures of the actual demands placed on the test panel. Acceleration is proportional to force, while velocity can be related to energy. Table 2 provides a summary of the shock table impact velocity, pulse-duration, and peak-deceleration; and the loading-mass peak-deceleration and maximum relative velocity (with respect to the shock table).

Table 2 Dynamic test summary of shock parameters and loading-mass measurements

\begin{tabular}{|llc|c|c|c|}
\hline Panel & \multicolumn{3}{c}{ Shock table measurements } & \multicolumn{2}{l}{ Loading-mass measurements } \\
\hline Number & $\begin{array}{l}\text { Impact } \\
\text { velocity } \\
\text { (m/s) }\end{array}$ & $\begin{array}{l}\text { Pulse-duration } \\
\text { (ms) }\end{array}$ & $\begin{array}{l}\text { Peak } \\
\text { deceleration } \\
\text { (\%g) }\end{array}$ & $\begin{array}{l}\text { Peak } \\
\text { deceleration } \\
(\% g)\end{array}$ & $\begin{array}{l}\text { Max relative } \\
\text { velocity } \\
\text { (m/s) }\end{array}$ \\
\hline CM-03-4W & 3.25 & 7.45 & 106.3 & 94.2 & 3.83 \\
\hline CM-04-4W & 3.24 & 7.80 & 95.1 & $*$ & 4.32 \\
\hline CM-05-CL & 3.23 & 7.5 & 94.2 & 129.5 & 1.78 \\
\hline CM-07-FB & 3.24 & 8.10 & 96.5 & 84.5 & 2.61 \\
\hline CM-08-FB & 3.21 & 8.00 & 95.3 & 63.4 & 2.94 \\
\hline CM-09-CL & 3.19 & 7.75 & 92.7 & 56.1 & 2.75 \\
\hline
\end{tabular}

* Measurement not available due to sensor malfunction

From Table 2, it can be seen that the shock table motion (impact velocity, pulse-duration, and shock amplitude) for each test is comparable, allowing for relative comparison between test results. The welded-wire panels were dropped twice because limited damage resulted from the initial drops.

A total of two panels reinforced with welded-wire mesh were tested. Panel CM-03-4W was tested with the reinforcement above the neutral axis, while $\mathrm{CM}-04-4 \mathrm{~W}$ was tested with the reinforcement located below the neutral axis. Figures 11 (a) and 11 (b) show the resulting damage after the first $3.2 \mathrm{~m} / \mathrm{s} \mathrm{impact.} \mathrm{It} \mathrm{is} \mathrm{important}$ to point out that panel CM-03-4W was the first panel tested, and was tested with only a $0.5 \mathrm{~cm}$ offset from the shock table. This limited deflection of the panel, restricting damage during the test. Panel CM-04-4W (and all proceeding tests) was tested with a $2.54 \mathrm{~cm}$ offset. While panel CM-03-4W was cracked nearly all the 
way through and had undergone visible panel deflection, CM-04-4W was minimally damaged, with only small, unopened fractures forming to about halfway through the panel.

Both panels were dropped a second time. CM-03-4W was re-dropped with a target impact velocity of $3.2 \mathrm{~m} / \mathrm{s}$, while CM-04-4W was re-dropped with a target impact velocity of $5.6 \mathrm{~m} / \mathrm{s}$ (loading-mass impact kinetic energy of $0.785 \mathrm{~kJ}$ ). Both panels were fully cracked, but survived the shock loading. Figures $12(\mathrm{a})$ and $12(\mathrm{~b})$ show damage to panel CM-03-4W and CM-04-4W, respectively, after the second drop.

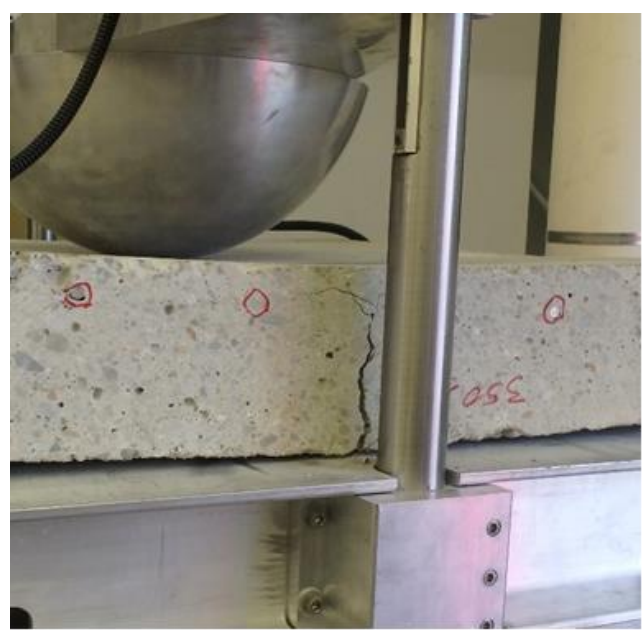

(a)

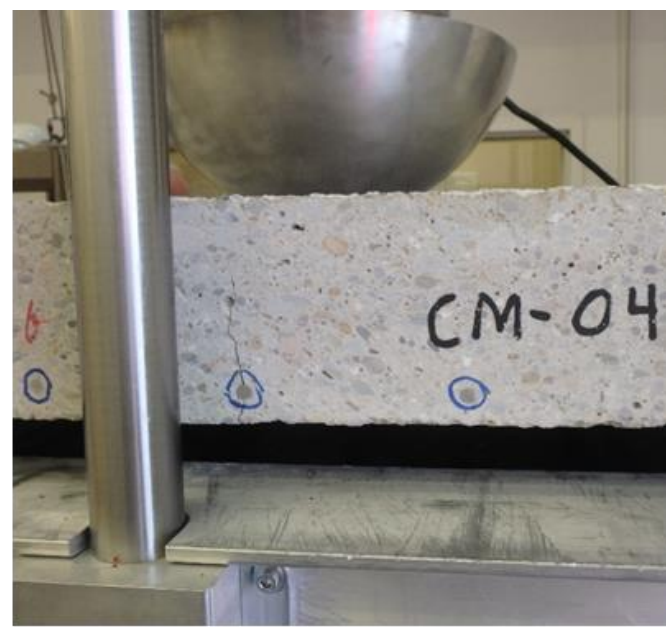

(b)

Figure 11 Post-test photos of $3.2 \mathrm{~m} / \mathrm{s}$ impact test on concrete reinforced with No. 4 gauge welded-wire located: (a) above the neutral axis; and, (b) below the neutral axis

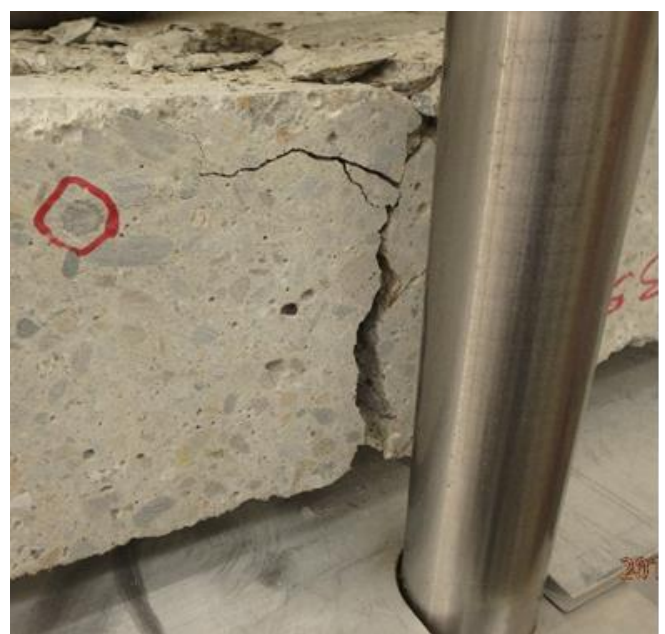

(a)

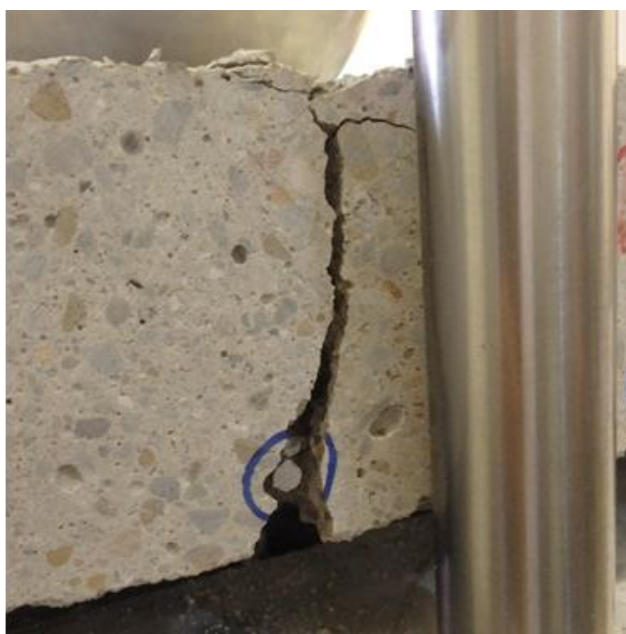

(b)

Figure 12 Post-test photos of second impact tests on concrete reinforced with No. 4 gauge welded-wire located: (a) above the neutral axis; and, (b) below the neutral axis

In another set of tests, two chain-link reinforced panels were tested. Panel CM-09-CL was tested with the reinforcement located above the neutral axis, while panel $\mathrm{CM}-05-\mathrm{CL}$ was tested with the reinforcement below the neutral axis. Figure 13 show the damage that occurred as a result of the impact $(3.2 \mathrm{~m} / \mathrm{s})$. The panel with the reinforcement located above the neutral axis (CM-09-CL) completely cracked through the concrete on all sides, deflecting the full $2.54 \mathrm{~cm}$ of clearance. The panel with the chain-link located below the neutral axis (CM-05-CL) was deflected significantly less. Visually, the damage induced in both chain-link panels was considerably more than that caused during the respective tests on welded-wire reinforced panels. The chain-link panels were not re-tested. 
A third set of two panel tests was performed on panels reinforced with synthetic macro-fibres. The panels deflected the full $2.54 \mathrm{~cm}$ as shown in Figure 14(a). In these tests, although some of the fibres were observed to pull through the shotcrete, the primary mode of failure appears to be fibre rupture, as is shown in Figure 14(b). This result contrasts with the quasi-static HEHD tests, using the same mix design, in which the primary failure mechanism was fibre pull-out (Raffaldi et al. 2016).

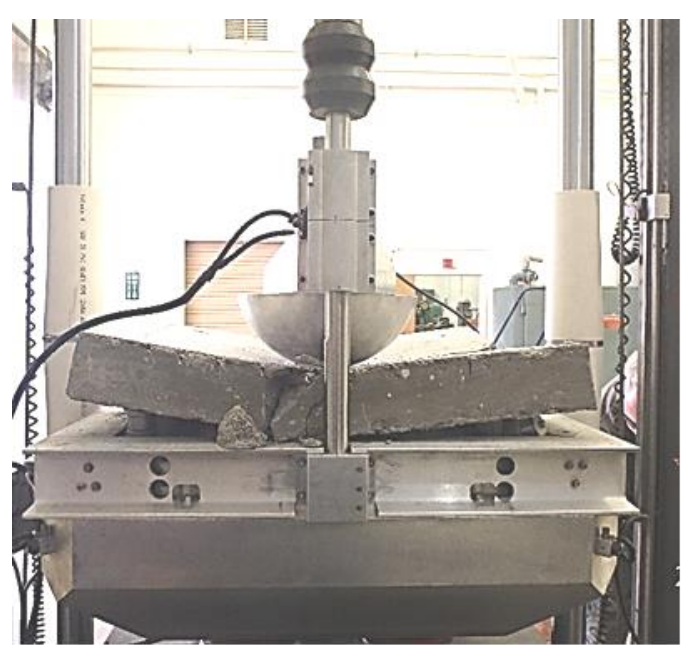

(a)

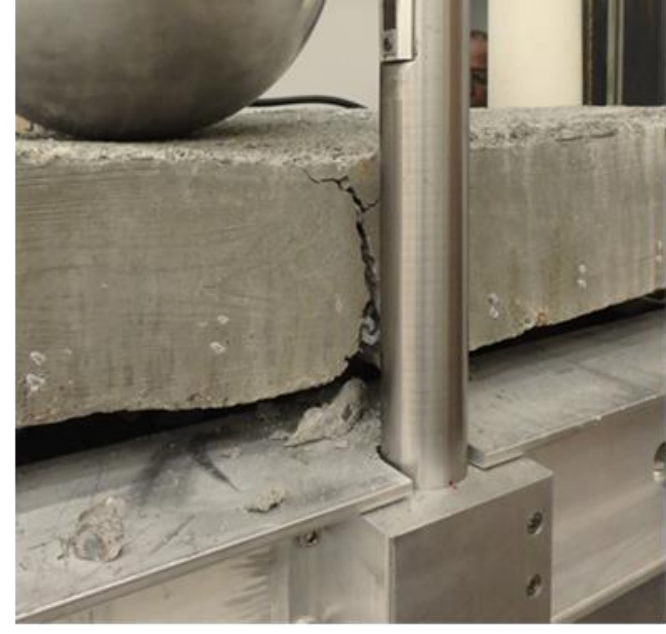

(b)

Figure 13 Post-test photos of $3.2 \mathrm{~m} / \mathrm{s}$ impact test on concrete reinforced with chain-link fence located: (a) above the neutral axis; and, (b) below the neutral axis

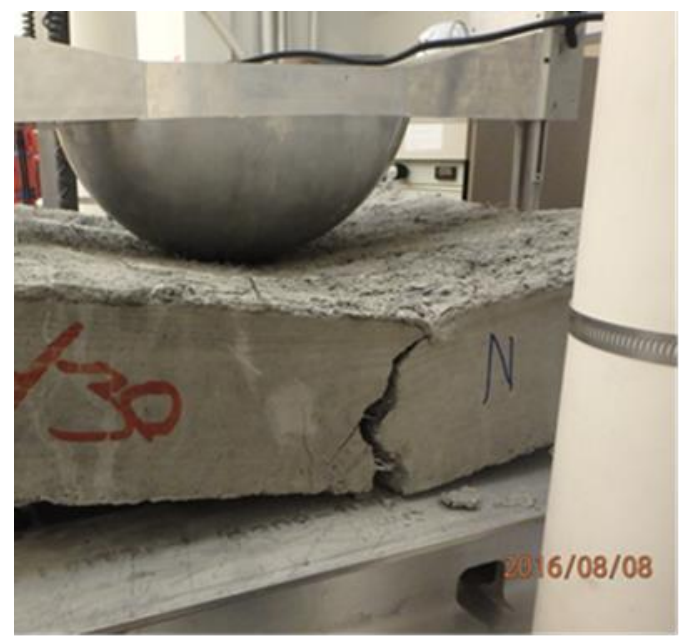

(a)

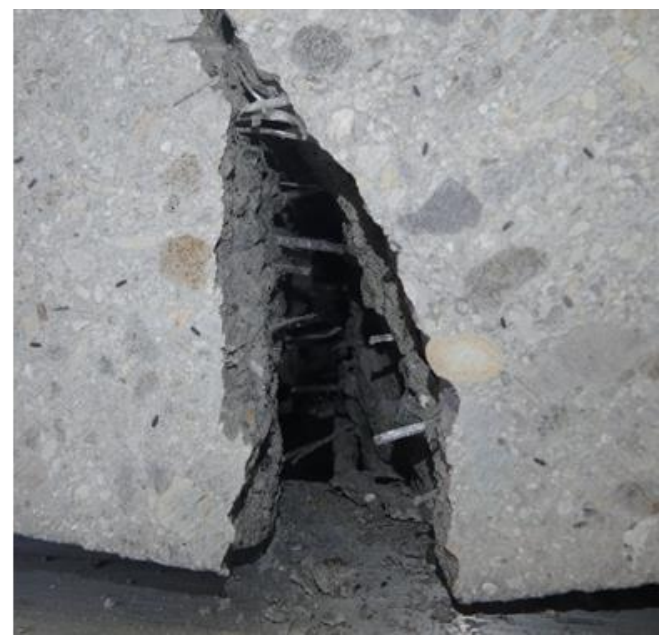

(b)

Figure 14 Post-test photos of $3.2 \mathrm{~m} / \mathrm{s}$ impact test on shotcrete with BarChip $544^{\circledR}$ synthetic fibres: (a) opened crack through panel; and (b) ruptured and crinkled fibres

Figure 15 shows the deceleration of the loading-mass versus time for the welded-wire and chain-link (reinforcement below neutral axis) panels and a fibre-mix panel resulting from an initial $3.2 \mathrm{~m} / \mathrm{s}$ drop. For the chain-link and fibre panels a clear, momentary drop in resistance is observed at the onset of concrete fracture. Then, the resistance increases again as the loads are redistributed to the chain-link and fibre. For the welded-wire panel, it appears that the reinforcement engages almost instantly, and resistance continues to increase. Although these plots cannot be directly compared with quasi-static force-displacement results, measuring deceleration, which can be converted to a reaction force (by multiplying by the loading-mass) may provide useful insight into the dynamic behaviour of reinforced concrete. At this time, however, a full analysis of these data has not been made. 


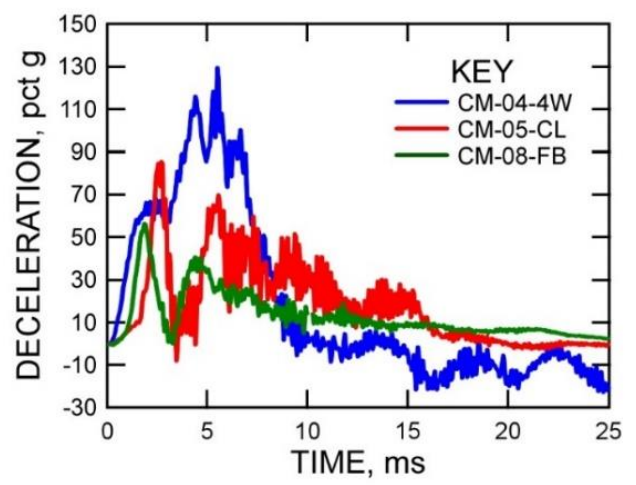

Figure 15 Loading-mass acceleration versus time for three test panels during dynamic shock tests

\section{Conclusion}

Two new testing machines are being used to study reinforced shotcrete surface support for underground mines: a large quasi-static panel testing machine, and a mechanical shock testing machine.

The large quasi-static panel testing machine is designed to determine the strength and energy capacity of shotcrete surface support between bolts at flexural displacements up to $25 \mathrm{~cm}$. Results of commissioning tests largely corroborate findings of past studies that fibre can provide good support characteristics up to $4 \mathrm{~cm}$ of flexural deflection, but where severe ground movements occur, some form of steel wire mesh is required. The combination of synthetic macro fibres with chain-link mesh was found to provide an ideal elastic-plastic support performance when the mesh is located well above the neutral-axis (on the loading side of the panel). Locating the mesh below the neutral-axis would likely increase the peak strength of the panel, but result in a stiffer system with less displacement capacity.

The limited number of tests performed using the dynamic shock test machine highlight the importance of using some form of steel reinforcement when dynamic loads are of concern. The large quasi-static tests and shock tests cannot be directly compared because of differences in dimensions and boundary conditions. Despite this, the change in failure mode of synthetic-fibre reinforced panels from fibre pull-out to a combination of pull-out and rupture when tested under quasi-static and dynamic conditions, respectively, shows how dynamic test results may complement quasi-static tests.

Full-scale fully-dynamic testing of steel-wire reinforced panels to maximum capacity is of interest, but the scale, boundary conditions, and panel displacement that can be accommodated by the available shock test machine is better compared to quality control tests such as the RDP test. Despite this limitation, advantages of this machine are that: several tests can be performed in a single workday, test conditions can be well controlled, and test conditions are repeatable. Further, the test is truly a dynamic test which takes into account the inertial effects of the concrete. The loading can easily be altered by changing programmers, allowing for the effect of the loading conditions (impact velocity, peak acceleration, and pulse-duration) to be investigated.

The long-term goal of the dynamic research is to investigate the conditions under which dynamic testing is truly required for understanding the dynamic response of reinforced shotcrete. Systemic testing of shotcrete panels subjected to a wide range of controlled dynamic conditions may provide insight into the response of this material to seismic loading. In the future, combining results from quasi-static tests with those from dynamic testing may provide insight regarding the use of reinforced shotcrete for surface support in rockburst conditions.

\section{Acknowledgement}

The authors thank Mike Johnson of Ragged Ridge Construction for his shotcrete nozzling work, Jess McDonald for his shotcrete placement and specialty form work. The authors also thank members of the SMRD staff: Seth Finley and Habte Abraham for their assistance with panel construction and testing, Jerry Richardson for assisting with instrumentation and electronics, and Curtis Clark for assistance with mechanical design. 


\section{Disclaimer}

The findings and conclusions in this paper are those of the author(s) and do not necessarily represent the views of the National Institute for Occupational Safety and Health (NIOSH). Mention of any company or product does not constitute endorsement by $\mathrm{NIOSH}$.

\section{References}

Benton, D, Boltz, M, Raffaldi, M \& Iverson, S 2015a, 'Using photogrammetry to monitor underground mining environments', ARMA e-Newsletter Special Issue: Imaging and Remote Sensing in Rock Mechanics, vol. spring 2015, no. 15, pp. 11-16.

Benton, D, Iverson, S, Martin, L, Johnson, JC \& Raffaldi, MJ 2015b, 'Volumetric measurement of rock movement using photogrammetry', Proceedings of the 33rd International Conference on Ground Control in Mining, Morgantown, West Virginia, pp. 8.

Bernard, ES 2010, 'High deformation load resistance of macro-synthetic fibre reinforced shotcrete', in Y Potvin (ed.), Proceedings of the Sixth International Conference on Deep and High Stress Mining, Australian Centre for Geomechanics, Perth, pp. 383-394.

Johansen, KW 1972, Yield Line Theory, Cement and Concrete Association, London.

Kirsten, H 1992, 'Comparative efficiency and ultimate strength of mesh and fibre-reinforced shotcrete as determined from full scale bending tests', Journal of the Southern African Institute of Mining and Metallurgy, vol. 92, pp. 303-323.

Kirsten, H 1993, 'Equivalence of mesh and fibre reinforced shotcrete at large deflections', Canadian Geotechnical Journal, vol. 30 , pp. 418-440.

Kirsten, HAD \& Labrum, PR 1990, 'The equivalence of fibre and mesh reinforcement in the shotcrete used in tunnel-support systems,' Journal of the South African Institute of Mining and Metallurgy, vol. 90, pp. 153-171.

Martin, L, Clark, C, Johnson, J \& Stepan, M 2015, 'A new high force and displacement shotcrete test', Proceedings of the Annual Meeting of the Society for Mining Metallurgy and Exploration, Denver, pp. 10.

Morgan, DR, Neere, R, McAskill, N, \& Chan, C 1999, 'Comparative evaluation of system ductility of mesh and fibre reinforced shotcretes', in Shotcrete for Underground Support VIII, Campos do Jordão, Brazil, pp. 23.

Morgan, DR, McAskill, N, Richardson, BW \& Zellers, RC 1989, 'A comparative evaluation of plain, polypropylene fiber, steel fiber, and wire mesh reinforced shotcrete', Transportation Research Record 1226, Transportation Research Board, USA, pp. 32.

Morton, EC, Thompson, AG \& Villaescusa, E 2007, 'Testing and analysis of steel wire mesh for mining applications of rock surface support', Proceedings of the 11th Congress of the International Society for Rock Mechanics, Lisbon, pp. 1061-1064.

Ortlepp, WD 1969, 'An empirical determination of the effectiveness of rockbolt support under impulse loading', Proceedings of the International Symposium on Large Permanent Underground Openings, Oslo, pp. 197-205.

Ortlepp, WD \& Stacey, TD 1998, 'Performance of tunnel support under large deformation static and dynamic loading', Tunnelling and Underground Space Technology, vol. 13, pp. 15-21.

Pakalnis, V \& Ames, D 1983, 'Load tests on mine screening', Underground Support Systems, special vol. 35, Canadian Institute of Mining Metallurgy and Petroleum, Westmount, pp. 79-83.

Player, JR, Morton, EC \& Villaescusa, E 2008, 'Static and dynamic testing of steel wire mesh for mining applications of rock surface support', Proceedings of the Sixth International Symposium on Ground Support in Mining and Civil Engineering Construction, Southern African Institute of Mining and Metallurgy, Johannesberg, pp. 693-706.

Player, JR, Thompson, AG \& Villaescusa, E 2004, 'Dynamic testing of rock reinforcement using the momentum transfer concept', in E Villaescusa \& Y Potvin (eds), Proceedings of the Fifth International Symposium on Ground Support, CRC Press, pp. $327-340$.

Potvin, Y, Wesseloo, J \& Heal, D 2010, 'An interpretation of ground support capacity submitted to dynamic loading', M Van Sint Jan \& Y Potvin (eds), Proceedings of the Fifth International Seminar on Deep and High Stress Mining, Australian Centre for Geomechanics, Perth, pp. 251-272.

Raffaldi, M, Benton, D, Martin, L, Johnson, J \& Stepan, M 2016, 'Toughness of large-scale shotcrete panels loaded in flexure', Transactions of the Society for Mining, Metallurgy and Exploration, vol. 340 (in press).

Soroushian, P \& Choi, K 1987, 'Steel mechanical properties at different strain rates', Journal of Structural Engineering, vol. 113, American Society of Civil Engineers, Reston, pp. 663-672.

Stacey, TR 2001, 'Review of membrane support mechanisms, loading mechanisms, desired membrane performance, and appropriate test methods', Journal of the Southern African Institute of Mining and Metallurgy, vol. 101, pp. 343-352.

Villaescusa, E, Thompson, AG \& Player, JR 2012, 'Static and dynamic testing of welded and woven mesh for rock support', in Y Potvin (ed.), Proceedings of the Sixth International Seminar on Deep and High Stress Mining, Australian Centre for Geomechanics, Perth, pp. 187-196.

Widijanto, E, Setiawan, E, Ramirez, M \& Napitupulu, D, 2010, 'Shotcrete application and optimization at PT Freeport Indonesia's Deep Ore Zone mine', in Bernard (ed.), Shotcrete: Elements of a System, Taylor \& Francis, London, pp. 283-289. 